\title{
Variability of Isoflavone Content in Soy Milk Products Commercially Available in Thailand
}

Ekkapon Hirattanapun ${ }^{1}$, Nut Koonrungsesomboon, M.D., Ph.D. ${ }^{1}$,

Supanimit Teekachunhatean, M.D., Ph.D. ${ }^{1,2}$

'Department of Pharmacology, ${ }^{2}$ Center of Thai Traditional and Complementary Medicine,

Faculty of Medicine, Chiang Mai University, Mueang, Chiang Mai 50200, Thailand.

Received 13 November 2017 • Accepted 19 December 2017 • Published online 24 May 2018

\section{Abstract:}

Objective: To determine the isoflavone content in soy milk products commercially available in Thailand.

Material and Methods: Two flavors of each of 4 brands of soy milk were obtained from retail outlets in Chiang Mai, Thailand. The isoflavone content in soy milk was determined using high-performance liquid chromatography.

Results: Genistin and daidzin, both $\beta$-glycoside conjugates, were found to be the main isoflavone components in soy milk. The total amount of isoflavones varied considerably among different products, ranging from 25.5 to $63.5 \mathrm{mg}$ per serving $(250 \mathrm{~mL})$ of soy milk. Marked variation in total isoflavones was also found even among different lots of the same product.

Conclusion: The isoflavone content in soy milk products available in Thailand varies substantially among different products as well as among different lots of the same product. This suggests that standardizing or, at least, declaring the isoflavone content in soy milk products is needed to facilitate the optimal consumption of soy milk for health benefits.

Keywords: isoflavones, soy milk, Thailand 


\section{Introduction}

Soy isoflavones represent the most common group of phytoestrogens and are structurally similar to $17 \beta-$ estradiol. ${ }^{1}$ They exhibit 3 aglycone structures, daidzein, genistein, and glycitein, each of which has a corresponding $\beta$-glycoside conjugate, i.e., daidzin, genistin, and glycitin, respectively, as well as acetyl and malonyl glycoside conjugates. ${ }^{2}$ Interest in isoflavones has increased owing to evidence that these phytoestrogens have a wide range of pharmacological activities. ${ }^{3}$ Promising data from clinical studies suggest beneficial effects of isoflavones for various health conditions, primarily those related to women's health. ${ }^{4}$ For example, systematic reviews and meta-analyses have demonstrated a significant reduction in the frequency and severity of menopausal hot flashes with regular consumption of isoflavones. ${ }^{5-8}$ In addition, isoflavones have exhibited potential health benefits in the prevention of osteoporosis and cardiovascular disease in menopausal women. ${ }^{9-11}$

Soybeans (Glycine max L. Merr.) and soy-based products are one of the richest food sources of isoflavones. ${ }^{12}$ Soy is found in traditional foods in many Asian countries, especially Japan, while in Western countries soy consumption has continuously increased over the last decade. ${ }^{13}$ At present, soy milk and other soy-based beverages are widely consumed worldwide and interest has grown because of the prospect of their beneficial properties in maintaining health and preventing diseases. ${ }^{14}$ However, in spite of the wide array of soy milk products commercially available on the market, there is only limited information available regarding soy isoflavone content in Thailand. This lack of information hinders the determination of the optimal consumption of soy milk as a healthful beverage.

The objective of the present study was to determine the isoflavone content of soy milk products commercially available in Thailand.

\section{Material and Methods}

\section{Soy milk product sampling}

Two flavors of each of 4 brands of soy milk (coded as $A_{1}, A_{2}, B_{1}, B_{2}, C_{1}, C_{2}, D_{1}, D_{2}$ ) were obtained from retail outlets in Mueang Chiang Mai district, Chiang Mai province, Thailand. For each product, 3 different lots (3 samples per lot) were randomly selected based on the expiry date displayed on the package: Lot 1 expired in August 2015, Lot 2 expired in October or November 2015, and Lot 3 expired in March 2016. None of the 8 soy milk product packages provided information on isoflavone content.

\section{Sample preparation}

Sample preparation was completed using a modified version of a method described in the Association of Official Agricultural Chemists (AOAC) Official Methods of Analysis. ${ }^{15}$ Using that method, $1 \mathrm{~mL}$ of soy milk was mixed with $9 \mathrm{~mL}$ of $80.0 \%$ methanol in water. Then, $350 \mu \mathrm{L}$ of $2 \mathrm{M} \mathrm{NaOH}$ was added and the mixture was sonicated for 30 minutesafter which $250 \mu \mathrm{L}$ of $100.0 \%$ acetic acid was added. One $\mathrm{mL}$ of the mixture was centrifuged. Ten $\mu \mathrm{L}$ of clear supernatant was then mixed with $30 \mu \mathrm{L}$ of mobile phase and spiked with $10 \mu \mathrm{L}$ of internal standard (IS, 10,000 $\mathrm{ng} / \mathrm{mL}$ of chloramphenicol). Five $\mu \mathrm{L}$ of the mixture was injected into a high-performance liquid chromatography (HPLC) system. Each sample was analyzed in triplicate.

\section{High-performance liquid chromatographic} condition

The assay used to quantify the isoflavones was modified from the isocratic reversed-phase HPLC method developed by Cesar Ida, et al. ${ }^{16}$ The chromatographic system consisted of a C18 reverse phase column (Inertsil ${ }^{\circledR}$, 250 mm x 4.6 I.D., 5 Hm, GL Science, Tokyo, Japan) equipped 
with a guard column of the same material (Inertsil ${ }^{\circledR}$ ODS-3, $10 \mathrm{~mm} \times 4.0$ I.D., 5 Hm, GL Science, Tokyo, Japan). The chromatographic analysis included a mobile phase $A$ $(0.1 \%$ acetic acid in water) and a mobile phase $B(100.0 \%$ methanol). Separation was performed at $40{ }^{\circ} \mathrm{C}$. Gradient elutions of $85.0 \% \mathrm{~A}$ with $15.0 \% \mathrm{~B}$ for $20 \mathrm{~min}, 30.0 \% \mathrm{~A}$ with $70.0 \%$ B for $5 \mathrm{~min}$, and $85.0 \% \mathrm{~A}$ with $15.0 \% \mathrm{~B}$ for $7 \mathrm{~min}$ were accomplished. The mobile phase was maintained at a flow rate of $1 \mathrm{~mL} / \mathrm{min}$, and the results were quantified by UV absorption at $259 \mathrm{~nm}$.

\section{Quantification of isoflavones and assay validation}

Standard $\beta$-glycosides (daidzin, genistin, and glycitin) and aglycones (daidzein, genistein, and glycitein) were spiked in serial dilution (in $100.0 \%$ methanol) to obtain a standard calibration curve. That curve ranged between 100 and 6,400 ng/mL for daidzin and genistin, and between 100 and 2,000 ng/mL for daidzein, genistein, glycitin, and glycitein. The HPLC chromatogram of standard isoflavones and their retention times are shown in Figure 1A. All peaks were clearly separated and no interference from other substances was observed. The regression equations for testing the linearity of the standard calibration curves are as follows:

$$
\begin{aligned}
& y=0.2706 x-1.1487\left(r^{2}=1.0000\right), \text { for daidzin } \\
& y=0.4055 x+2.0608\left(r^{2}=0.9999\right), \text { for genistin } \\
& y=0.2252 x-0.0279\left(r^{2}=0.9999\right), \text { for glycitin } \\
& y=0.4117 x-0.8728 \quad\left(r^{2}=0.9996\right), \text { for daidzein } \\
& y=0.5420 x-0.2867\left(r^{2}=0.9996\right), \text { for genistein } \\
& y=0.2808 x+1.2273\left(r^{2}=0.9998\right), \text { for glycitein }
\end{aligned}
$$

The isoflavone content of the soy milk samples were determined using a calibration curve of the peak height ratios of isoflavones and using the linear regression of an internal standard versus respective isoflavone concentrations.

The lower limit of quantification (LLOQ) of the 6 isoflavones under the HPLC conditions described above was $100 \mathrm{ng} / \mathrm{mL}$, which is the lowest concentration of an analyte that can be reliably measured. Of the 5 samples spiked at $100 \mathrm{ng} / \mathrm{mL}$ each, the average coefficients of variation (\% CV) at the LLOQ concentration (calculated using Equation (1) for daidzin, genistin, glycitin, daidzein, genistein, and glycitein were $2.0 \%, 1.2 \%, 2.6 \%, 0.2 \%, 0.5 \%$, and $2.4 \%$, respectively. The average \% deviation at LLOQ concentration (calculated using Equation 2) for those 6 isoflavones were $0.7 \%, 7.5 \%, 5.6 \%, 8.1 \%, 7.9 \%$, and $5.3 \%$, respectively.

(Equation 1)

$$
\% \mathrm{CV}=\frac{\text { Standard deviation }}{\text { Mean }} \times 100
$$

(Equation 2)

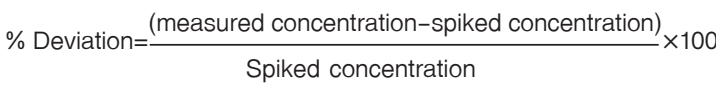

Intraday and interday validation procedures were carried out to assess the precision of the technique. For intraday validation, 5 samples from each of 3 quality control (QC) samples (300, 2,500, and 5,000 ng/mL of daidzin and genistin; 300,900 , and $1,800 \mathrm{ng} / \mathrm{mL}$ of daidzein, genistein, glycitin, and glycitein) were evaluated with a single calibration curve. For interday validation, 5 sets of the 3 different concentrations of QC samples were studied concurrently on 5 different days with 5 standard calibration curves. The \% CV (calculated using Equation 1) and \% deviation (calculated using Equation 2) of intraday and interday assay validation for 6 isoflavonesare shown in Table 1. None of the \% CV values were above $6.2 \%$, and none of the $\%$ deviation values were greater than $9.4 \%$ or less than $-7.8 \%$.

\section{Data analysis}

Descriptive analysis was performed; the quantities of isoflavone content are presented as mean $( \pm$ standard 
deviation; S.D.) per one serving (250 $\mathrm{mL})$ of soy milk. The values of isoflavones in the form of $\beta$-glycoside conjugates used in the following text refer to the aglycone equivalent weights.
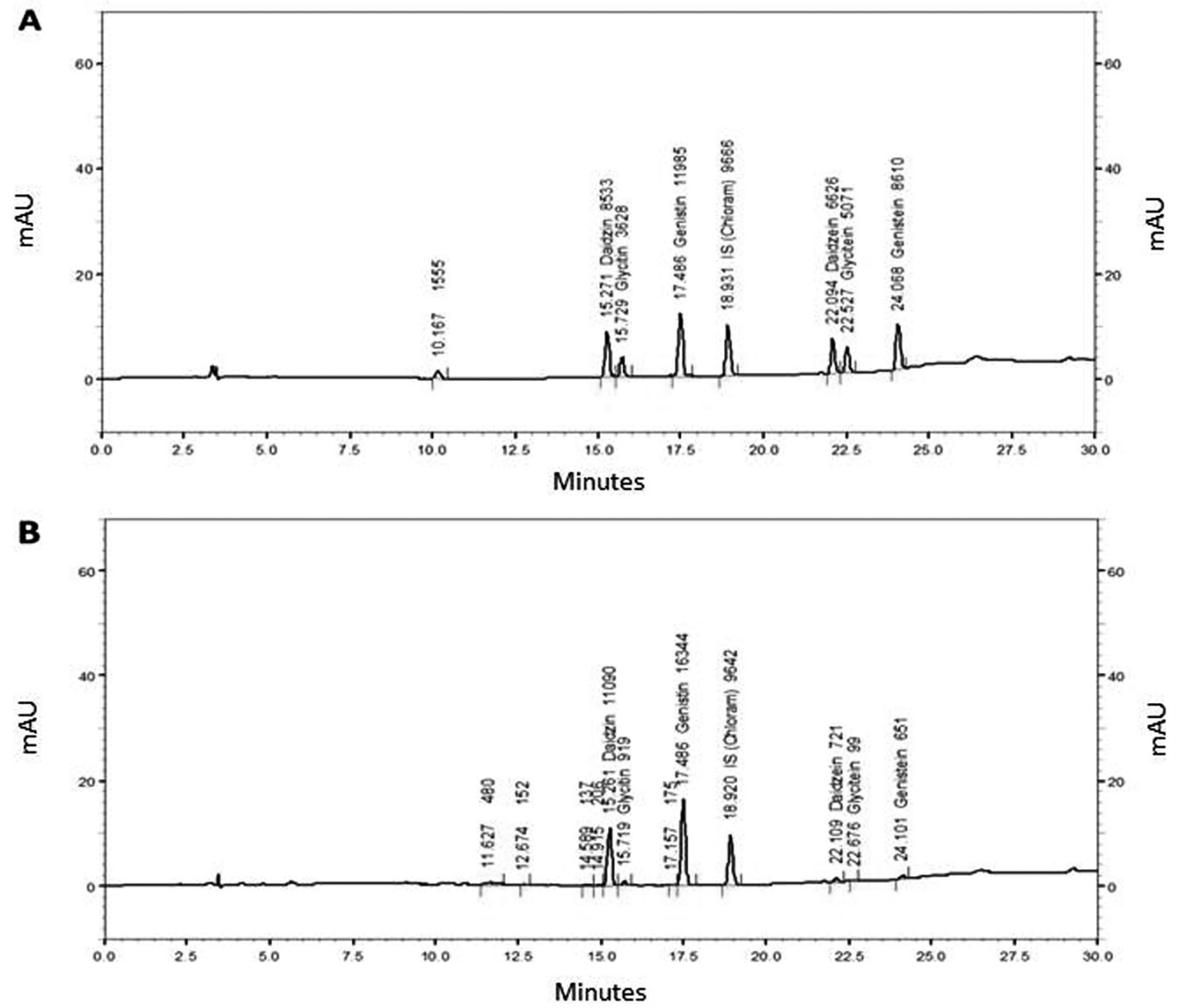

Figure 1 HPLC chromatograms of (A) standard isoflavones $(3,200 \mathrm{ng} / \mathrm{mL}$ of daidzin and genistin; 1,600 $\mathrm{ng} / \mathrm{mL}$ of daidzein, genistein, glycitin, and glycitein) and $(B)$ isoflavone content in soy milk (a sample from $D_{1}$ ). 
Table 1 Intraday and interday assay validation of isoflavone content measurements

\begin{tabular}{|c|c|c|c|c|c|}
\hline \multirow{2}{*}{ Isoflavones } & \multirow{2}{*}{$\begin{array}{l}\text { Concentration of } Q C \\
\text { sample }(n g / m L)\end{array}$} & \multicolumn{2}{|c|}{ Intraday } & \multicolumn{2}{|c|}{ Interday } \\
\hline & & Precision (\% CV) & Deviation (\%) & Precision (\% CV) & Deviation (\%) \\
\hline \multirow[t]{3}{*}{ Daidzin } & 300 & 1.5 & 3.1 & 4.2 & 3.9 \\
\hline & 2,500 & 0.2 & 2.1 & 2.9 & 2.8 \\
\hline & 5,000 & 0.5 & 1.0 & 4.7 & 0.8 \\
\hline \multirow[t]{3}{*}{ Genistin } & 300 & 0.7 & 8.8 & 1.2 & 7.3 \\
\hline & 2,500 & 0.3 & 9.4 & 0.7 & 8.9 \\
\hline & 5,000 & 0.6 & 8.9 & 3.3 & 7.2 \\
\hline \multirow[t]{3}{*}{ Glycitin } & 300 & 0.9 & -3.6 & 1.5 & -5.2 \\
\hline & 900 & 1.5 & -1.6 & 3.0 & -5.5 \\
\hline & 1,800 & 2.7 & -0.1 & 4.3 & -4.0 \\
\hline \multirow[t]{3}{*}{ Daidzein } & 300 & 0.9 & -5.8 & 2.2 & -5.6 \\
\hline & 900 & 0.6 & -1.6 & 3.1 & -4.1 \\
\hline & 1,800 & 0.4 & 1.9 & 5.6 & -4.2 \\
\hline \multirow[t]{3}{*}{ Genistein } & 300 & 1.0 & -4.4 & 2.0 & -4.6 \\
\hline & 900 & 1.3 & -2.4 & 3.7 & -5.0 \\
\hline & 1,800 & 1.8 & 1.7 & 6.2 & -4.4 \\
\hline \multirow[t]{3}{*}{ Glycitein } & 300 & 0.9 & -1.6 & 1.7 & -2.3 \\
\hline & 900 & 1.3 & -6.4 & 1.0 & -7.8 \\
\hline & 1,800 & 0.5 & 5.4 & 5.2 & 0.0 \\
\hline
\end{tabular}

$C V=$ the coefficient of variation, $Q C=$ quality control

\section{Resullts}

The HPLC chromatogram of isoflavone content in soymilk is shown in Figure 1B. The mean quantities of total isoflavones in soy milk products varied widely, from $25.5 \mathrm{mg}$ (in $\mathrm{B}_{1}$ ) to $63.5 \mathrm{mg}$ (in $\mathrm{D}_{2}$ ) per $250 \mathrm{~mL}$ of product (Table 2). Marked variation in total isoflavones among different lots of the same product was found across all brands, with the calculated \% CV ranging from 17.7 (in $B_{1}$ ) to 43.3 (in $A_{1}$ ) (Figure 2). In all the brands except $B$, the amount of total isoflavones in Lot 2 was lower than Lot 1 and Lot 3 . However, total isoflavone content among the same lot of the same product did not vary to a great extent for any of the soy milk products (\% CV=0.2-5.5) (Figure 2).

The majority of isoflavones in soy milk were in the form of $\beta$-glycoside conjugates, accounting for approximately $84.0-97.0 \%$ of the total isoflavones (Table 2). Genistein, daidzein, and glycitein and their $\beta$-glycoside forms accounted for 55.5\% (S.D.=5.7), 40.1\% (S.D.=3.5), and $4.4 \%$ (S.D.=2.5), respectively, of the total isoflavone content (Table 2 and Figure 3 ). The ratios of genistein and its $\beta$-glycoside conjugateto total isoflavones varied 
from 0.5 to 0.6 while those of daidzein and its $\beta$-glycoside conjugate were between 0.4 and 0.5 (Figure 3 ). The amount of genistein and its $\beta$-glycoside form was higher than daidzein and its $\beta$-glycoside form in all products.

Table 2 Isoflavone content of the 8 soy milk products investigated in this study

\begin{tabular}{|c|c|c|c|c|c|c|c|}
\hline \multirow{3}{*}{$\begin{array}{l}\text { Soy milk } \\
\text { product }\end{array}$} & \multicolumn{6}{|c|}{ Isoflavone content ( $\mathrm{mg} / 250 \mathrm{~mL}$ of soy milk) } & \multirow{3}{*}{ Total } \\
\hline & \multicolumn{3}{|c|}{$\boldsymbol{\beta}$-glycosides } & \multicolumn{3}{|c|}{ Aglycones } & \\
\hline & Daidzin* & Genistin* & Glycitin* & Daidzein & Genistein & Glycitein & \\
\hline$A_{1}$ & $13.5( \pm 5.6)$ & $24.8( \pm 10.6)$ & $0.2( \pm 0.3)$ & $1.5( \pm 0.8)$ & $1.8( \pm 1.5)$ & $0.0( \pm 0.0)$ & $41.8( \pm 18.1)$ \\
\hline $\mathrm{A}_{2}$ & $12.2( \pm 3.4)$ & $22.5( \pm 4.3)$ & $0.1( \pm 0.2)$ & $1.4( \pm 0.3)$ & $1.6( \pm 0.8)$ & $0.1( \pm 0.1)$ & $37.9( \pm 8.1)$ \\
\hline $\mathrm{B}_{1}$ & $8.3( \pm 2.9)$ & $11.6( \pm 1.5)$ & $1.5( \pm 0.2)$ & $1.9( \pm 1.1)$ & $2.2( \pm 1.3)$ & $0.0( \pm 0.0)$ & $25.5( \pm 4.5)$ \\
\hline $\mathrm{B}_{2}$ & $9.7( \pm 3.5)$ & $14.1( \pm 3.2)$ & $1.8( \pm 0.5)$ & $2.0( \pm 1.3)$ & $2.1( \pm 1.3)$ & $0.0( \pm 0.0)$ & $29.7( \pm 8.5)$ \\
\hline $\mathrm{C}_{1}$ & $23.2( \pm 1.9)$ & $34.4( \pm 12.4)$ & $2.8( \pm 0.5)$ & $0.7( \pm 0.2)$ & $0.6( \pm 0.1)$ & $0.3( \pm 0.2)$ & $61.9( \pm 14.0)$ \\
\hline $\mathrm{C}_{2}$ & $21.4( \pm 11.6)$ & $28.2( \pm 10.4)$ & $3.0( \pm 0.7)$ & $1.5( \pm 0.9)$ & $1.4( \pm 0.9)$ & $0.4( \pm 0.2)$ & $56.0( \pm 24.0)$ \\
\hline $\mathrm{D}_{1}$ & $25.9( \pm 13.4)$ & $29.0( \pm 10.0)$ & $3.3( \pm 0.7)$ & $1.6( \pm 0.9)$ & $1.2( \pm 0.6)$ & $0.4( \pm 0.1)$ & $61.3( \pm 25.6)$ \\
\hline $\mathrm{D}_{2}$ & $26.9( \pm 13.5)$ & $30.1( \pm 9.8)$ & $3.3( \pm 0.6)$ & $1.6( \pm 0.9)$ & $1.3( \pm 0.6)$ & $0.3( \pm 0.2)$ & $63.5( \pm 25.4)$ \\
\hline $\begin{array}{l}\text { Inter-product } \\
\text { variation (\% CV) }\end{array}$ & 42.7 & 32.6 & 66.9 & 26.4 & 33.7 & 97.8 & 32.5 \\
\hline
\end{tabular}

Data are presented as mean ( \pm standard deviation) of isoflavone content (for each type, $n=9: 3$ lots, 3 samples per lot).

${ }^{*}$ Data represent content in aglycone equivalent weight.

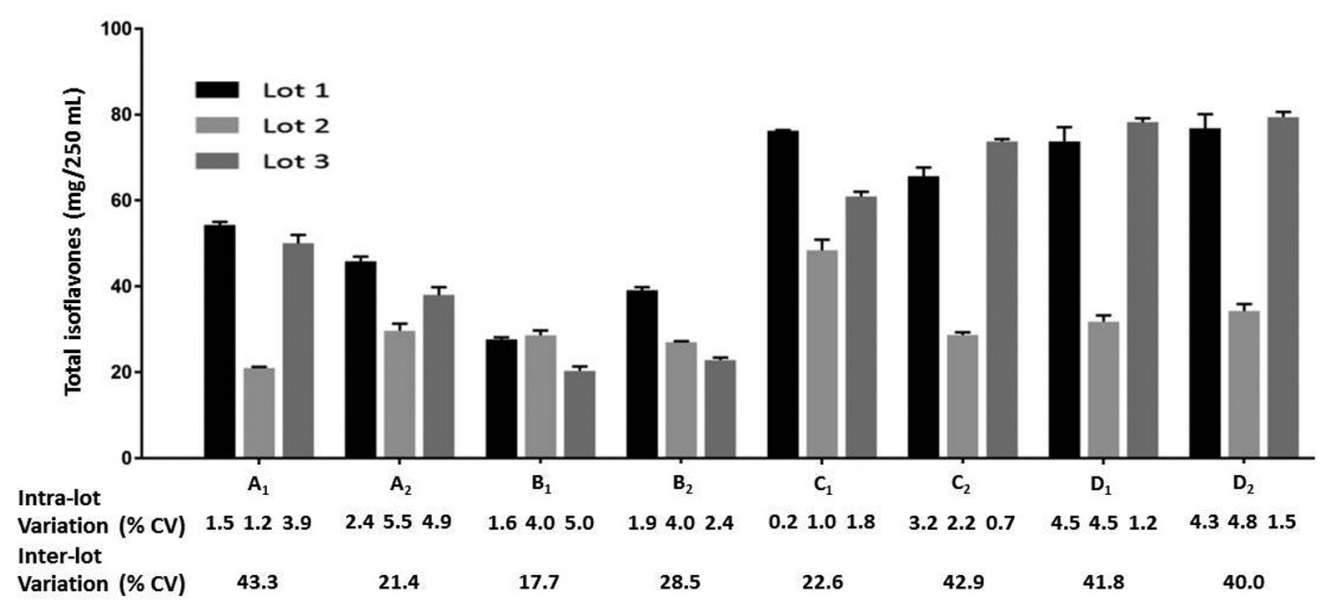

Figure 2 Total isoflavones in the 8 soy milk products ( 3 samples per lot) investigated in this study 


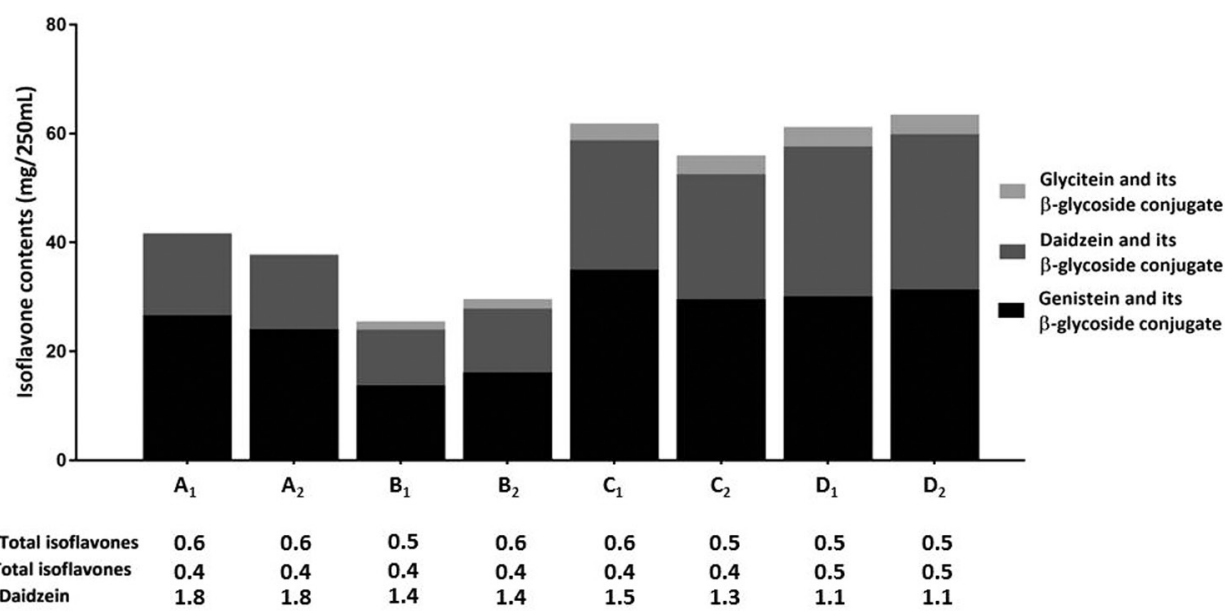

Figure 3 Proportion of each aglycone and its corresponding $\beta$-glycoside conjugate to total isoflavones in the 8 soy milk products ( $n=9$ : 3 lots, 3 samples per lot) investigated in this study

\section{Discussion}

The present study found substantial variation in total and individual isoflavone content among the 8 soy milk products commercially available in Thailand. The value of total isoflavones in 1 serving $(250 \mathrm{~mL})$ of soy milk in this study is comparable to the range of values (5 to 96 mg per $250 \mathrm{~mL}$ ) for soy-based beverages previously reported. ${ }^{17-19}$ The variation in the quantity of soy isoflavones commonly observed might be attributable to several factors. Differences in the characteristics of soybeans used (e.g., soy variety, seed quality, planting location, crop year, and even planting dates within the same crop year), manufacturing methods (e.g., soaking, grinding, and heating processing), storage conditions, as well as the quality of beans used per $250 \mathrm{~mL}$ serving could contribute to the considerable variation in isoflavone content in soymilk. ${ }^{20-23}$ The present study found a large difference in isoflavone content among lots of the same product, while the content within lots did not vary greatly. Based on this observation, it is reasonable to postulate that the key factors contributing to extensive variation in isoflavone content in soy milk include the characteristics of the raw material (i.e., seed variety and quality) rather than the largely standardized manufacturing methods and storage conditions. This finding indicates that producing soy milk products with standardized isoflavone content would be a challenging task for manufacturers.

The majority of the isoflavones found in soymilk were $\beta$-glycosides (i.e., genistin and daidzin), while small amounts of the aglycone forms were detected in all the products. This observation is compatible with the current knowledge of soy isoflavones: isoflavones in nonfermented soy-based products appear predominantly in the form of glycoside conjugates. ${ }^{24,25}$ Although the isoflavone content investigated in this study was limited to the $\beta$-glycoside conjugates and aglycones, this should have only a negligible effect on the total isoflavone content in soy milk, as published studies suggest that isoflavones in the form of malonyl- and acetyl-glycoside conjugates are generally converted into $\beta$-glycoside forms during soy milk prepa- 
ration. $^{26,27}$ Additionally, available evidence clearly shows that basic hydrolysis, which was applied during sample preparation, would break ester bonds and convert the malonyl- and acetyl-glycoside isoflavone forms to their respective $\beta$-glucosides. ${ }^{28}$ The ratio of genistein and its $\beta$-glycoside conjugate to daidzein and its $\beta$-glycoside conjugate observed in the present study was around $1: 1$ to $2: 1$, which is comparable to Thai soybean varieties reported in previous research. ${ }^{29}$

Genistein and its $\beta$-glycoside conjugate were the main isoflavones in soy milk, accounting for $49.0-64.0 \%$ of the total isoflavones. Variations in the proportion (or the amount) of genistein and its glycoside conjugate in different soy milk products may be of clinical relevance, since lines of evidence suggest that genistein appears to be the most biologically active component, responsible for the beneficial effects of isoflavones in soy-based products. ${ }^{30,31}$ At least $15 \mathrm{mg} /$ day (in aglycone equivalents) of genistein consistently contributed to a significant reduction in the symptoms of hot flashes in several clinical trials. ${ }^{32,33}$ Furthermore, the administration of genistein (54 mg/day) for a year was found to exhibit significant positive effects on bone mineral density in osteopenic menopausal and postmenopausal women. ${ }^{34,35}$ Although isoflavones in soy milk appear mainly in the $\beta$-glycoside form (genistin) rather than the aglycone form (genistein), this seems to have only modest effects on health benefits because genistein wouldbe absorbed in equal amounts irrespective of whether the glycoside form or the aglycone form had been initially consumed. ${ }^{36-38}$ The presence of the sugar moiety in the $\beta$-glycoside form may only delay the absorption rate of genistein while having no significant effect on the total absorption of isoflavones. ${ }^{36}$

Based on the results of this study, one glass of soy milk $(250 \mathrm{~mL})$ would result in an intake of around $25-60$ $\mathrm{mg}$ of total isoflavones, which is consistent with the results of a recent evaluation of the epidemiologic literature. ${ }^{39}$ That value is at least equivalent to the Japanese daily intake of isoflavones from soybeans and soy-based foods (an estimated $28 \mathrm{mg} /$ day). ${ }^{40}$ The literature suggests that the daily dose of total isoflavones that would benefit menopausal health by reducing the frequency and severity of hot flashes, ${ }^{5,6}$ as well as preventing osteoporosis ${ }^{10}$ and cardiovascular disease, ${ }^{11}$ is about $40-100 \mathrm{mg}$ (in aglycone equivalent weight). Thus, the daily consumption of 1-3 servings of soy milk (250 mL/serving) would be required to obtain the potential health benefits from soy isoflavones, if soy milk were the sole isoflavone source in the diet.

Given the growing interest in and increasing consumption of soy-based beverages, it would be useful to consumers if nutritional details regarding isoflavone content were provided on the packaging of soy milk products. Accurate labelling of isoflavone content would provide a valuable reference for the rational consumption of soy isoflavones and could have an impact on consumers' dietary choices. The information would also help researchers more accurately estimate isoflavone consumptionand facilitate epidemiological studies ofthe beneficial health effects of soy isoflavones.

\section{Conclusion}

The isoflavone content in soy milk products commercially available in Thailand varies substantially among different products, as well as among different lots of the same product. This suggests a need to standardize isoflavone content in soy milk, or at least to declare the isoflavone content on the package, in order to help consumers and nutritionists determine the intake of soy milk sufficient for obtaining health benefits from soy isoflavones. 


\section{Acknowledgment}

The authors would like to thank Mr. Boonyium Kumsornand Ms. Sujitra Techatoei for their supervision in analysis and assay validation of isoflavone content. The authors are grateful to Dr. G. Lamar Robert for his assistance in editing the manuscript.

This work received financial support from the Faculty of Medicine, Chiang Mai University, Thailand.

\section{Disclosures statement}

The authors declare that there are no conflicts of interest regarding the publication of this article. None of the authors have a direct financial relationship with any of the commercial entities mentioned in this paper.

\section{References}

1. Setchell KD. Phytoestrogens: the biochemistry, physiology, and implications for human health of soy isoflavones. Am $J$ Clin Nutr 1998;68(6 Suppl):S1333-46.

2. Wang $\mathrm{H}$, Murphy PA. Isoflavone content in commercial soybean foods. J Agric Food Chem 1994;42:1666-73.

3. Zaheer K, Humayoun Akhtar M. An updated review of dietary isoflavones: nutrition, processing, bioavailability and impacts on human health. Crit Rev Food Sci Nutr 2017;57:1280-93.

4. Messina M. Soy foods, isoflavones, and the health of postmenopausal women. Am J Clin Nutr 2014;100(Suppl 1):S423-30.

5. Taku K, Melby MK, Kronenberg F, Kurzer MS, Messina M. Extracted or synthesized soybean isoflavones reduce menopausal hot flash frequency and severity: systematic review and meta-analysis of randomized controlled trials. Menopause 2012;19:776-90.

6. Howes LG, Howes JB, Knight DC. Isoflavone therapy for menopausal flushes: a systematic review and meta-analysis. Maturitas 2006;55:203-11.

7. Franco OH, Chowdhury R, Troup J, Voortman T, Kunutsor S, Kavousi M, et al. Use of plant-based therapies and menopausal symptoms: asystematic review and meta-analysis. JAMA 2016;315:2554-63.

8. Sarri G, Pedder H, Dias S, Guo Y, Lumsden MA. Vasomotor symptoms resulting from natural menopause: a systematic review and network meta-analysis of treatment effects from the National Institute for Health and Care Excellence guideline on menopause. BJOG 2017;124:1514-23.

9. Ma DF, Qin LQ, Wang PY, Katoh R. Soy isoflavone intake increases bone mineral density in the spine of menopausal women: meta-analysis of randomized controlled trials. Clin Nutr 2008;27:57-64.

10. Taku K, Melby MK, Takebayashi J, Mizuno S, Ishimi Y, Omori T, et al. Effect of soy isoflavone extract supplements on bone mineral density in menopausal women: meta-analysis of randomized controlled trials. Asia Pac J Clin Nutr 2010;19: 33-42.

11. Hodis HN, Mack WJ, Kono N, Azen SP, Shoupe D, HwangLevine $\mathrm{J}$, et al. Isoflavone soy protein supplementation and atherosclerosis progression in healthy postmenopausal women: a randomized controlled trial. Stroke 2011;42:316875 .

12. Gacek M. Soy and legume seeds as sources of isoflavones: selected individual determinants of their consumption in a group of perimenopausal women. Prz Menopauzalny 2014;13: 27-31.

13. Barrett JR. The science of soy: what do we really know? Environ Health Perspect 2006;114:A352-8.

14. Sethi S, Tyagi SK, Anurag RK. Plant-based milk alternatives an emerging segment of functional beverages: a review. J Food Sci Technol 2016;53:3408-23.

15. Klump SP, Allred MC, MacDonald JL, Ballam JM. Determination of isoflavones in soy and selected foods containing soy by extraction, saponification, and liquid chromatography: collaborative study. J AOAC Int 2001;84:1865-83.

16. Cesar Ida C, Braga FC, Soares CD, Nunan Ede A, Pianetti GA, Condessa FA, et al. Development and validation of a RPHPLC method for quantification of isoflavone aglycones in hydrolyzed soy dry extracts. J Chromatogr B Analyt Technol Biomed Life Sci 2006;836:74-8.

17. Genovese MI, Lajolo FM. Isoflavones in soy-based foods consumed in Brazil: levels, distribution, and estimated intake. J Agric Food Chem 2002;50:5987-93.

18. Teekachunhatean S, Rojanasthien N, Sangdee C. Isoflavone contents in UHT and fresh soymilk available in amphur Muang, Chiang Mai. Chiang Mai Med Bull 2004;43:151-61. 
19. Techatoei S, Sangdee C, Rojanasthien N, Manorot M, Teekachunhatean S. Isoflavone contents in Thai and imported soybased beverages commercially available in Thailand. Chiang Mai Med Bull 2011;50:59-72.

20. Lee SJ, Ahn JK, Kim SH, Kim JT, Han SJ, Jung MY, et al. Variation in isoflavone of soybean cultivars with location and storage duration. J Agric Food Chem 2003;51:3382-9.

21. Eisen B, Ungar $Y$, Shimoni E. Stability of isoflavones in soy milk stored at elevated and ambient temperatures. J Agric Food Chem 2003;51:2212-5.

22. Xu Z, Wu Q, Godber JS. Stabilities of daidzin, glycitin, genistin, and generation of derivatives during heating. J Agric Food Chem 2002;50:7402-6.

23. Zhang J, Ge Y, Han F, Li B, Yan S, Sun J, et al. Isoflavone content of soybean cultivars from maturity group 0 to $\mathrm{VI}$ grown in northern and southern China. J Am Oil Chem Soc 2014;91:1019-28.

24. Wiseman H, Casey K, Clarke DB, Barnes KA, Bowey E. Isoflavone aglycon and glucoconjugate content of high- and low-soy U.K. foods used in nutritional studies. J Agric Food Chem 2002;50:1404-10.

25. Nguyen HT, Pourian M, Bystrom B, Dahlin I, Duc PT, Nguyen TV, et al. Low aglycone content in commercial soy drink products. Asia Pac J Clin Nutr 2012;21:52-6.

26. Jackson CJC, Dini JP, Lavandier C, Rupasinghe HPV, Faulkner H, Poysa V, et al. Effects of processing on the content and composition of isoflavones during manufacturing of soy beverage and tofu. Process Biochem 2002;37:1117-23.

27. Barnes S, Kirk M, Coward L. Isoflavones and their conjugates in soy foods: extraction conditions and analysis by HPLC-mass spectrometry. J Agric Food Chem 1994;42:2466-74.

28. Delmonte P, Perry J, Rader Jl. Determination of isoflavones in dietary supplements containing soy, Red Clover and kudzu: extraction followed by basic or acid hydrolysis. J Chromatogr A 2006;1107:59-69.

29. Teekachunhatean S, Hanprasertpong N, Teekachunhatean T. Factors affecting isoflavone content in soybean seeds grown in Thailand. Int J Agronomy 2013;2013: Article ID 163573, 11 pages.
30. McCarty MF. Isoflavones made simple - genistein's agonist activity for the beta-type estrogen receptor mediates their health benefits. Med Hypotheses 2006;66:1093-114.

31. Marini H, Bitto A, Altavilla D, Burnett BP, Polito F, Di Stefano V, et al. Breast safety and efficacy of genistein aglycone for postmenopausal bone loss: a follow-up study. J Clin Endocrinol Metab 2008;93:4787-96.

32. Lethaby A, Marjoribanks J, Kronenberg F, Roberts H, Eden J, Brown J. Phytoestrogens for menopausal vasomotor symptoms. Cochrane Database Syst Rev 2013:CD001395.

33. Williamson-Hughes PS, Flickinger BD, Messina MJ, Empie MW. Isoflavone supplements containing predominantly genistein reduce hot flash symptoms: a critical review of published studies. Menopause 2006;13:831-9.

34. Marini $\mathrm{H}$, Minutoli L, Polito F, Bitto A, Altavilla D, Atteritano M, et al. Effects of the phytoestrogen genistein on bone metabolism in osteopenic postmenopausal women: a randomized trial. Ann Intern Med 2007;146:839-47.

35. Morabito N, Crisafulli A, Vergara C, Gaudio A, Lasco A, Frisina $\mathrm{N}$, et al. Effects of genistein and hormone-replacement therapy on bone loss in early postmenopausal women: a randomized double-blind placebo-controlled study. J Bone Miner Res 2002;17:1904-12.

36. Kano M, Takayanagi T, Harada K, Sawada S, Ishikawa F. Bioavailability of isoflavones after ingestion of soy beverages in healthy adults. J Nutr 2006;136:2291-6.

37. Xu X, Wang HJ, Murphy PA, Hendrich S. Neither background diet nor type of soy food affects short-term isoflavone bioavailability in women. J Nutr 2000;130:798-801.

38. Zubik L, Meydani M. Bioavailability of soybean isoflavones from aglycone and glucoside forms in American women. Am J Clin Nutr 2003;77:1459-65.

39. Messina M. Soy and health update: evaluation of the clinical and epidemiologic literature. Nutrients 2016;8:E754.

40. Nakamura Y, Tsuji S, Tonogai Y. Determination of the levels of isoflavonoids in soybeans and soy-derived foods and estimation of isoflavonoids in the Japanese daily intake. J AOAC Int 2000; 83:635-50. 